\title{
INFORMÁTICA E AVALIAÇÃO NA EDUCAÇÃO A DISTÂNCIA NA UFRGS: UM PANORAMA DE 1998 A 2008.
}

\author{
Luís Fernando Maximo ${ }^{1}$ \\ Dante Augusto Couto Barone ${ }^{1}$ \\ Marie Jane Soares Carvalho ${ }^{1}$ \\ ${ }^{1}$ Programa de Pós-graduação em Informática na Educação - PGIE/UFRGS \\ fernandomax@univali.br; barone@inf.ufrgs.br; mcarvalho@ rocketmail.com.
}

\section{Resumo}

O objetivo desse artigo é descrever um panorama da divulgação e produção científica na Universidade Federal do Rio Grande do Sul - UFRGS - envolvendo o tema informática e avaliação na educação a distância. O estudo envolve uma análise dos materiais disponíveis por meio do acesso à internet sob o domínio "ufrgs.br" e na Biblioteca Digital de Teses e Dissertações da UFRGS. As questões que buscamos relatar giram em torno de que tipo de enfoque avaliativo tem sido abordado, que autores tem sido usados para fundamentar tal abordagem e qual o enfoque dos trabalhos em termos de tecnologia proposta ou empregada. Entre os critérios para seleção de materiais foram estabelecidos: a data, entre 1998 e 2008, e a ênfase na avaliação dos alunos. Entre os resultados mais significativos encontrados estão: a maior ocorrência dos enfoques avaliativos do tipo formativo e a ênfase das pesquisas sobre o rastreamento das ações dos alunos em ambientes informatizados para ações de avaliação formativa.

\section{Palavras-chave}

Informática - Avaliação - Educação a Distância

\section{Computers and Assessment in Distance Education at UFRGS: a view since 1998 to 2008.}

\begin{abstract}
This paper aims to describe the scientific production about computers and assessment in distance education at the Federal University of Rio Grande do Sul - UFRGS. The study involves an analysis of the materials available via the Internet access under the domain "ufrgs.br" and the Digital Library of Theses and Dissertations of UFRGS. We searched the type of evaluative approach that has been addressed, that author has been used to justify this approach and what the focus of work in terms of technology employed or proposal. The criteria of material's selection were: the date, since 1998 to 2008, and emphasis on student's assessment. The most significant results found: the predominant occurrence of focus on formative evaluation and research centred about tracking actions of students in computer environments to the formative assessment.
\end{abstract}

\section{Key-words}

Computers - Assessment - Distance Education

V. 6 № 1, Julho, 2008 


\section{INTRODUÇÃO}

Um dos assuntos mais polêmicos e delicados no contexto da educação a distância é a avaliação. Geralmente, a preocupação está em torno de uma avaliação que possa assegurar o acompanhamento, não só do desempenho, mas, principalmente, da aprendizagem dos alunos. Pallof e Pratt (2004), ao comentarem sobre sua experiência de contato com diversos professores envolvidos na educação a distância afirmam que um dos assuntos que causam maior pressão é o que diz respeito à avaliação dos alunos.

Do atual momento das instituições e políticas educacionais no Brasil sobre educação a distância é possível extrairmos dois pontos que podem reforçar a importância de focarmos nossas atenções na questão da avaliação.

Em primeiro lugar está a acelerada expansão e proliferação de cursos a distância, principalmente na educação superior, em todo Brasil. Os resultados do último censo da educação superior divulgados pelo Instituto Nacional de Estudos e Pesquisas Educacionais Anísio Teixeira - INEP - em dezembro de 2007 mostram que, de 2003 a 2006, houve um aumento de $571 \%$ em número de cursos a distância e de $315 \%$ no número de matrículas. Os dados do censo apontam ainda que, em 2005, os alunos de EAD representavam 2,6\% do universo dos estudantes e, em 2006, essa participação passou a ser de 4,4\%. (INEP, 2007).

Um segundo ponto é, na verdade, uma preocupação de que, diante da forte concorrência existente no mercado educacional, algumas instituições de ensino superior passem a optar pela oferta de cursos a distância como forma de redução de custos e sustentação. Tal visão da educação a distância é um grande equívoco e torna as ações de avaliação ainda mais frágeis em face de um contingente de alunos cada vez maior em relação ao número de professores e tutores disponibilizados para acompanhá-los e orientá-los.

Pensar a avaliação num cenário de expansão da educação a distância parece essencial para que tenhamos mais garantias de um futuro de sucesso para essa modalidade educacional. E, quando aqui nos referimos a sucesso queremos dizer possibilitar aos alunos condições de acompanhamento e aprendizagem, independente de termos uma relação de quantidade alunos/tutor mais conservadora ou em larga escala.

A avaliação, segundo Azzi (2006), desempenha funções legitimas e indispensáveis no processo educativo. Sua função mais evidente é a pedagógica, que visa, principalmente, a verificação da aprendizagem dos alunos, a identificação de suas necessidades e a regulação ou melhoria do processo de ensino aprendizagem. Ferreira, Otsuka e Rocha (2003) destacam a especial importância, no contexto da educação a distância, de uma avaliação formativa, ou seja, com características informativa e reguladora. De acordo com as autoras, na avaliação formativa o professor é informado dos efeitos reais de suas ações, podendo regular sua ação pedagógica. O aprendiz tem oportunidade de tomar consciência de suas dificuldades e, possivelmente, reconhecer e corrigir seus próprios erros. Estas características possibilitam que os professores, mesmo a distância, percebam as dificuldades de seus aprendizes e os orientem efetivamente.

Acreditamos que a informática pode contribuir de forma efetiva nos processos avaliativos em cursos a distância. Tal contribuição pode vir da combinação de diferentes recursos. Ferramentas de comunicação mediada por computador, técnicas de 
inteligência artificial, sumarização rápida de informações sobre os alunos, objetos de aprendizagem, ambientes virtuais.

Mas, o que temos hoje em termos de pesquisa e produção científica na área da Informática na Educação sobre avaliação na educação a distância?

Posta essa questão, cabe informar que o objetivo desse artigo é descrever um panorama da produção científica envolvendo o tema informática e avaliação na educação a distância nos últimos dez anos. As questões que buscamos relatar giram em torno de que tipo de enfoque avaliativo tem sido abordado, que autores tem sido usados para fundamentar tal abordagem e qual o enfoque dos trabalhos em termos de tecnologia proposta ou empregada.

$\mathrm{O}$ artigo está organizado em três seções além da Introdução. Na seção Metodologia serão detalhados o recorte, a forma, os critérios e os materiais utilizados para estudo. Os resultados encontrados, bem como a discussão dos mesmos a partir de teóricos da área da Avaliação estão na seção Resultados e Discussão. Ao final do texto apresentamos a seção Considerações Finais e em seguida as referências bibliográficas utilizadas.

\section{METODOLOGIA}

Os materiais analisados no presente estudo foram obtidos a partir de buscas na internet limitadas ao domínio "ufrgs.br" e também a partir de buscas na Biblioteca Digital de Teses e Dissertações da UFRGS. Para a busca limitada ao domínio "ufrgs.br" foi utilizado o site de buscas Google. Como argumentos para as buscas no Google foram utilizados os seguintes conjuntos de expressões:

- Avaliação +EAD + Aprendizagem site:ufrgs.br

- Avaliação +"Educação a Distância" + Aprendizagem site:ufrgs.br

- Avaliação +"Ensino a Distância" +Aprendizagem site:ufrgs.br

Juntamente com a busca na Biblioteca Digital de Teses e Dissertações da UFRGS foram encontrados mais de 800 registros. A pesquisa foi realizada entre os dias 20/04/2008 e 01/05/2008. Dos registros encontrados, após a leitura dos mesmos, selecionamos apenas aqueles materiais que tratavam especificamente da questão avaliação dos alunos e que estivessem datados entre 1998 e 2008. Não constam, portanto, nos resultados, trabalhos relacionados, por exemplo, a avaliação institucional ou avaliação de cursos ou que tenham data anterior a 1998.

A UFRGS foi escolhida como alvo - recorte - de nossa pesquisa dado o seu renome e reconhecimento como centro de divulgação e produção científica na área da Informática na Educação. Certamente essa metodologia não esgota a abrangência de todas as pesquisas, artigos, teses e dissertações da UFRGS, mas acreditamos que tenha representatividade suficiente para tecermos algumas análises e conclusões.

A partir dos materiais selecionados construímos um quadro cuja estrutura está ilustrada pela Tabela 1 a seguir.

Tabela 1 - Estrutura do quadro "Panorama do tema Informática e Avaliação na Educação a Distância na UFRGS”.

\begin{tabular}{|c|c|c|c|c|}
\hline Título & Ano & Autores & Enfoque & Enfoque do \\
\hline
\end{tabular}

V. 6 № 1, Julho, 2008 


\begin{tabular}{|l|l|l|l|l|}
\hline & & Utilizados & Avaliativo & Trabalho \\
\hline & & & & \\
\hline
\end{tabular}

A forma de preenchimento do quadro "Panorama do Tema Informática e Avaliação na Educação a Distância na UFRGS" que será apresentado na seção Resultados e Discussão como Tabela 2 está descrita a seguir.

Nas colunas Título e Ano foram colocados, respectivamente, o título e o ano dos materiais analisados.

Na coluna Autores Utilizados aparecem os nomes de autores utilizados nos materiais analisados para referenciar ou fundamentar as questões envolvendo avaliação. Importante ressaltar que registramos no quadro apenas as referências aos autores de obras claramente identificadas como sendo sobre o tema Avaliação. Quando esse tipo de referência não foi encontrado preenchemos o campo com a expressão "Não explicitado".

Para o preenchimento da coluna Enfoque Avaliativo definimos algumas categorias a partir da literatura sobre avaliação.

A avaliação pode ser classificada quanto aos seus objetivos e resultados. Bloom (1983), por exemplo, classifica a avaliação em diagnóstica, somativa e formativa. Hadji (2001), apresenta sua classificação como avaliação prognostica, avaliação formativa e avaliação cumulativa.

O tipo de avaliação diagnóstica ou prognóstica envolve a avaliação que antecede o processo formativo. Como seu próprio nome sugere, permite construir um diagnóstico da situação dos alunos e ajuda no planejamento ou correção das ações pedagógicas.

Já as avaliações do tipo somativa ou cumulativa são aquelas que ocorrem ao final do processo de aprendizagem com o objetivo de certificar o aprendizado dos alunos. São frequientemente usadas como forma de medir e classificar os alunos a partir de seus desempenhos em provas e outros instrumentos de avaliação.

A avaliação do tipo formativa, por sua vez, é aquela que ocorre durante todo o processo de aprendizagem e que permite a sua regulação, sintonia ou refinamento.

Para Hadji (1993, p. 125), o objetivo da avaliação do tipo formativa é o de "permitir ajustar o tratamento didático à natureza das dificuldades constatadas e à realidade dos progressos registrados". Ou seja, acompanhar o processo de aprendizagem e, a partir de registros de avanços e dificuldades, regular a trajetória dos alunos rumo aos objetivos estabelecidos ou desejados.

Apenas como esclarecimento, quando utilizamos a expressão regulação estamos acompanhando o pensamento de Hadji (1993), de que a regulação é uma atividade pedagógica e a avaliação é o seu suporte, ou um dos seus momentos. A regulação corresponde às orientações dadas aos alunos e aos ajustes feitos na ação pedagógica para o alcance dos objetivos planejados. Corresponde, inclusive, ao ajuste dos objetivos.

Dentre as classificações de avaliação encontradas na literatura, adotamos para o preenchimento da coluna Enfoque Avaliativo as seguintes categorias: diagnóstico, V. 6 № 1 , Julho, 2008 
somativo e formativo. No caso da categoria formativo promovemos uma divisão entre formativo direto e formativo indireto.

Podemos encontrar no pensamento de Perrenoud sobre avaliação formativa, uma distinção quanto ao tipo de regulação da aprendizagem possibilitado pelo processo formativo. De um lado temos a regulação da aprendizagem em si. De outro temos a regulação das condições de aprendizagem. Para Perrenoud (1999), todas as intervenções do professor, de forma mais ou menos direta, favorecem supostamente as aprendizagens. Entretanto, faz uma distinção entre o que chama de regulação direta dos processos de aprendizagem, que passa por intervenções no funcionamento intelectual do aluno envolvido numa tarefa, da "regulação indireta, que age sobre as condições de aprendizagem: motivação, participação, implicação no trabalho, ambiente, estruturação da tarefa e da situação didática" (PERRENOUD, 1999, p. 80).

Tendo como base a distinção feita por Perrenoud entre regulação direta e indireta da aprendizagem estabelecemos que, no que diz respeito ao enfoque formativo da avaliação, a coluna Enfoque Avaliativo foi preenchida com:

- Formativo (Direto): quando nos materiais analisados foram encontradas situações relacionadas ao uso registros de exercícios, questionários e outras atividades de aprendizagem como subsídio para análise, acompanhamento e retorno para o aluno.

- Formativo (Indireto): quando nos materiais analisados foram encontradas situações relacionadas ao uso de registros de participação, freqüência, estados afetivos e outros registros similares como subsídio para análise, acompanhamento e retorno para o aluno.

Ainda sobre a coluna Enfoque Avaliativo, também foi definida uma categoria Geral - para representar trabalhos nos quais não foi possível identificar o enfoque avaliativo ou que apenas abordam o tema de forma geral.

Resumindo, as categorias definidas para o preenchimento da coluna Enfoque Avaliativo foram as seguintes: diagnóstico, somativo, formativo (direto), formativo (indireto) e geral.

Finalmente, a coluna Enfoque do Trabalho, procuramos preencher com informações sobre o tipo de proposta de uso e/ou desenvolvimento de tecnologias em favor do acompanhamento e regulação do processo de aprendizagem.

Tendo sido detalhados o recorte de nosso estudo, os critérios de obtenção dos materiais para análise e a forma como foram tratados, apresentamos a seguir uma consolidação das análises feitas, bem como, uma discussão destas.

\section{RESULTADOS E DISCUSSÃO}

A Tabela 2, a seguir, apresenta uma consolidação das análises realizadas a partir da leitura dos materiais encontrados na internet sob as condições já expostas na seção anterior.

Tabela 2 - Panorama do tema informática e avaliação na educação a distância na UFRGS.

\begin{tabular}{|l|l|l|l|l|}
\hline Título & Ano & Autores Utilizados & Enfoque & Enfoque do Trabalho \\
\hline
\end{tabular}

V. 6 № 1, Julho, 2008 


\begin{tabular}{|c|c|c|c|c|}
\hline & & & Avaliativo & \\
\hline $\begin{array}{l}\text { Mecanismos } \\
\text { complementares para a } \\
\text { avaliação do aluno na } \\
\text { educação a distância }\end{array}$ & 1999 & $\begin{array}{l}\text { BLOOM; } \\
\text { KIRKPATRICK. }\end{array}$ & $\begin{array}{l}\text { Diagnóstico } \\
\text { Formativo } \\
\text { (Indireto) }\end{array}$ & $\begin{array}{l}\text { Ferramentas para o } \\
\text { rastreamento do } \\
\text { envolvimento e } \\
\text { participação do } \\
\text { aluno. }\end{array}$ \\
\hline $\begin{array}{l}\text { Avaliação no ensino à } \\
\text { distância via web }\end{array}$ & 1999 & $\begin{array}{l}\text { Celso VASCONCELOS; } \\
\text { Jussara HOFFMAN. }\end{array}$ & Geral & $\begin{array}{l}\text { Proposta de ambiente } \\
\text { para avaliação na } \\
\text { web. }\end{array}$ \\
\hline $\begin{array}{l}\text { Agente avaliação de ensino } \\
\text { e aprendizagem em EAD }\end{array}$ & 2000 & Não explicitado. & $\begin{array}{l}\text { Formativo } \\
\text { (Direto) }\end{array}$ & $\begin{array}{l}\text { Desenvolvimento de } \\
\text { agentes para auxílio } \\
\text { na avaliação. }\end{array}$ \\
\hline $\begin{array}{l}\text { Alertas inteligentes na } \\
\text { educação a distância }\end{array}$ & 2000 & Não explicitado. & $\begin{array}{l}\text { Formativo } \\
\text { (Indireto) }\end{array}$ & $\begin{array}{l}\text { Ferramentas para } \\
\text { rastreamento do } \\
\text { envolvimento, uso de } \\
\text { recursos e } \\
\text { participação dos } \\
\text { alunos. }\end{array}$ \\
\hline $\begin{array}{l}\text { AMON-AD: um agente } \\
\text { inteligente para avaliação } \\
\text { de aprendizagem em } \\
\text { ambientes baseados na } \\
\text { Web }\end{array}$ & 2000 & $\begin{array}{l}\text { Francesco BARTOLOMEIS; } \\
\text { BLOOM; } \\
\text { Lea DEPRESBITERIS; } \\
\text { LUCKESI. }\end{array}$ & $\begin{array}{l}\text { Formativo } \\
\text { (Direto) }\end{array}$ & $\begin{array}{l}\text { Rastreamento ou } \\
\text { monitoramento de } \\
\text { registros de } \\
\text { aprendizagem. }\end{array}$ \\
\hline $\begin{array}{l}\text { Um modelo do aluno } \\
\text { adaptativo para sistemas na } \\
\text { web }\end{array}$ & 2000 & Não explicitado. & $\begin{array}{l}\text { Formativo } \\
\text { (Indireto) }\end{array}$ & $\begin{array}{l}\text { Rastreamento ou } \\
\text { monitoramento de } \\
\text { registros de } \\
\text { aprendizagem. } \\
\text { Adaptação de } \\
\text { Ambientes. }\end{array}$ \\
\hline $\begin{array}{l}\text { Um experimento com } \\
\text { agentes de software para } \\
\text { monitorar a colaboração } \\
\text { em aulas virtuais }\end{array}$ & 2000 & Não explicitado. & $\begin{array}{l}\text { Formativo } \\
\text { (Indireto) }\end{array}$ & $\begin{array}{l}\text { Desenvolvimento de } \\
\text { agentes e ferramentas } \\
\text { para rastreamento da } \\
\text { participação e das } \\
\text { interações entre } \\
\text { alunos. }\end{array}$ \\
\hline $\begin{array}{l}\text { O processo de avaliação na } \\
\text { educação a distância }\end{array}$ & 2001 & Benjamin BLOOM. & Geral & $\begin{array}{l}\text { Comparação entre } \\
\text { Ambientes Virtuais. }\end{array}$ \\
\hline $\begin{array}{l}\text { Uso de agentes de interface } \\
\text { no ambiente TelEduc }\end{array}$ & 2003 & $\begin{array}{l}\text { PERRENOUD; } \\
\text { HADJI. }\end{array}$ & $\begin{array}{l}\text { Formativo } \\
\text { (Indireto) }\end{array}$ & $\begin{array}{l}\text { Desenvolvimento de } \\
\text { agentes e ferramentas } \\
\text { para rastreamento da } \\
\text { participação e das } \\
\text { interações entre } \\
\text { alunos. }\end{array}$ \\
\hline $\begin{array}{l}\text { Produção coletiva em rede: } \\
\text { é possível avaliar? }\end{array}$ & 2003 & Maria Teresa ESTEBAN. & $\begin{array}{l}\text { Formativo } \\
\text { (Indireto) }\end{array}$ & $\begin{array}{l}\text { Revisão e reflexão } \\
\text { sobre o processo de } \\
\text { avaliação e } \\
\text { rastreamento de } \\
\text { registros para } \\
\text { avaliação. }\end{array}$ \\
\hline $\begin{array}{l}\text { Webduc: uma proposta de } \\
\text { ferramenta de avaliação } \\
\text { formativa no ambiente } \\
\text { TelEduc }\end{array}$ & 2004 & PERRENOUD. & $\begin{array}{l}\text { Formativo } \\
\text { (Direto) }\end{array}$ & $\begin{array}{l}\text { Proposta de ambiente } \\
\text { para avaliação na } \\
\text { web - criação de } \\
\text { exercícios e retorno } \\
\text { imediato. }\end{array}$ \\
\hline $\begin{array}{l}\text { Busca de um modelo de } \\
\text { avaliação no curso de }\end{array}$ & 2004 & Jussara HOFFMANN; & Geral & $\begin{array}{l}\text { Revisão e reflexão } \\
\text { sobre o processo de }\end{array}$ \\
\hline
\end{tabular}

V. 6 № 1, Julho, 2008 


\begin{tabular}{|c|c|c|c|c|}
\hline $\begin{array}{l}\text { Licenciatura em } \\
\text { Matemática a distância }\end{array}$ & & Maria LERCH. & & avaliação. \\
\hline $\begin{array}{l}\text { Disponibilização de } \\
\text { exercícios e sua correção } \\
\text { on-line }\end{array}$ & 2004 & Não explicitado & Somativo & $\begin{array}{l}\text { Disponibilização e } \\
\text { correção automática } \\
\text { de exercícios. }\end{array}$ \\
\hline $\begin{array}{l}\text { Um modelo de suporte à } \\
\text { avaliação formativa para } \\
\text { ambientes de EaD: dos } \\
\text { conceitos à solução } \\
\text { tecnológica }\end{array}$ & 2005 & $\begin{array}{l}\text { PERRENOUD; } \\
\text { HADJI. }\end{array}$ & $\begin{array}{l}\text { Formativo } \\
\text { (Indireto) }\end{array}$ & $\begin{array}{l}\text { Desenvolvimento de } \\
\text { agentes e ferramentas } \\
\text { para rastreamento da } \\
\text { participação e das } \\
\text { interações entre } \\
\text { alunos. }\end{array}$ \\
\hline $\begin{array}{l}\text { AVALWEB - Sistema } \\
\text { interativo para gerência de } \\
\text { questões - e aplicação de } \\
\text { avaliação na web }\end{array}$ & 2005 & $\begin{array}{l}\text { Benjamim BLOOM; } \\
\text { Regina Cazux HAYDT. }\end{array}$ & $\begin{array}{l}\text { Formativo } \\
\text { (Direto) }\end{array}$ & $\begin{array}{l}\text { Sistema de Gerência } \\
\text { de Questões - Auto- } \\
\text { avaliação - Feedback } \\
\text { Imediato - } \\
\text { explicações do } \\
\text { sucesso ou erro nas } \\
\text { respostas - ênfase ao } \\
\text { processo. }\end{array}$ \\
\hline $\begin{array}{l}\text { EASy - Recuperação de } \\
\text { questões através de } \\
\text { metadados e geração } \\
\text { automática de instrumentos } \\
\text { de avaliação via web. }\end{array}$ & 2005 & $\begin{array}{l}\text { Benjamin S. BLOOM; } \\
\text { Regina C. HAYDT; } \\
\text { E. B. MEDEIROS. }\end{array}$ & $\begin{array}{l}\text { Formativo } \\
\text { (Direto) }\end{array}$ & $\begin{array}{l}\text { Autoria de questões, } \\
\text { visando geração } \\
\text { automática de } \\
\text { avaliações. Recursos } \\
\text { adaptativos e } \\
\text { feedback para alunos. }\end{array}$ \\
\hline $\begin{array}{l}\text { Análise das interações em } \\
\text { ambientes virtuais de } \\
\text { aprendizagem: uma } \\
\text { possibilidade para } \\
\text { avaliação da aprendizagem } \\
\text { em EAD }\end{array}$ & 2006 & $\begin{array}{l}\text { Celso VASCONCELOS; } \\
\text { Jussara HOFFMAN. }\end{array}$ & $\begin{array}{l}\text { Formativo } \\
\text { (Indireto) }\end{array}$ & $\begin{array}{l}\text { Ferramentas para } \\
\text { rastreamento das } \\
\text { interações entre } \\
\text { alunos. }\end{array}$ \\
\hline $\begin{array}{l}\text { Uma linguagem visual para } \\
\text { avaliação adaptativa de } \\
\text { aprendizagem baseada em } \\
\text { Gramática de Grafos }\end{array}$ & 2006 & R.Z. CERNY. & $\begin{array}{l}\text { Formativo } \\
\text { (Direto) }\end{array}$ & $\begin{array}{l}\text { Sistema de Gerência } \\
\text { de Questões - } \\
\text { Facilitar a construção } \\
\text { de questões e } \\
\text { exercícios pelos } \\
\text { professores - } \\
\text { Aplicação pelos } \\
\text { alunos com feedback } \\
\text { imediato. }\end{array}$ \\
\hline $\begin{array}{l}\text { Avaliação em processos de } \\
\text { educação problematizadora } \\
\text { online }\end{array}$ & 2006 & Não explicitado. & Geral & $\begin{array}{l}\text { Revisão e reflexão } \\
\text { sobre o processo de } \\
\text { avaliação. }\end{array}$ \\
\hline $\begin{array}{l}\text { Comportamento adaptativo } \\
\text { baseado no caminho de } \\
\text { aprendizagem do estudante } \\
\text { em um Ambiente Virtual } \\
\text { de Ensino Aprendizagem - } \\
\text { AVEA }\end{array}$ & 2007 & Não explicitado. & $\begin{array}{l}\text { Formativo } \\
\text { (Direto) }\end{array}$ & $\begin{array}{l}\text { Rastreamento de } \\
\text { registros de } \\
\text { aprendizagem. }\end{array}$ \\
\hline $\begin{array}{l}\text { Reconhecimento de estados } \\
\text { afetivos do aluno em } \\
\text { ambientes virtuais de } \\
\text { aprendizagem }\end{array}$ & 2007 & Não explicitado. & $\begin{array}{l}\text { Formativo } \\
\text { (Indireto) }\end{array}$ & $\begin{array}{l}\text { Rastreamento de } \\
\text { estados afetivos. }\end{array}$ \\
\hline
\end{tabular}




CINTED-UFRGS
\begin{tabular}{|l|l|l|l|}
\hline & 8 & Novas Tecnologias na Educação \\
\hline $\begin{array}{l}\text { MEDIATEC - Mediação } \\
\text { tecnológica em espaços } \\
\text { virtuais para apoio ao } \\
\text { professor online }\end{array}$ & 2007 & Não explicitado. & $\begin{array}{l}\text { Rastreamento de } \\
\text { registros de } \\
\text { (Direto) } \\
\text { aprendizagem. } \\
\text { Adaptação de } \\
\text { Ambientes. }\end{array}$ \\
\hline
\end{tabular}

Na Tabela 2, é possível observar imediatamente que a questão do uso da informática como suporte aos processos avaliativos é uma preocupação recorrente ao longo do período analisado, exceto em 1998 e 2008. Este último ainda no seu período inicial.

Outra questão que chama atenção da Tabela 2 é a grande ocorrência de trabalhos que não fazem referência direta a autores e obras sobre o tema Avaliação. É verdade que, entre estes, alguns dos trabalhos ancoram-se nos teóricos de aprendizagem e desenvolvimento como Piaget e Vigotski, por exemplo, mas, não são maioria.

Essa é uma questão que poderia ser observada com mais cuidado pelos pesquisadores e desenvolvedores interessados em avaliação na educação a distância. $\mathrm{O}$ uso de obras específicas talvez possa permitir uma maior sintonia entre $o$ desenvolvimento de ambientes e ferramentas informatizadas com os diversos instrumentos, estratégias e desafios já discutidos e apontados pelos estudiosos da avaliação.

Entretanto, nos trabalhos que utilizaram referências e obras específicas sobre avaliação, encontramos a ocorrência do uso de autores clássicos e consagrados. Entre os mais citados estão: Bloom, Perrenoud, Hadji, Vasconcelos e Hoffman.

No que diz respeito ao Enfoque Avaliativo encontramos um predomínio do enfoque formativo da avaliação. Isso é muito interessante e animador, pois, embora a avaliação formativa seja importante para qualquer modalidade de ensino, é na educação a distância, como combustível do processo de mediação da aprendizagem, que ela se torna fundamental.

Podemos observar, na Tabela 2 , que existe um relativo equilíbrio entre os enfoques formativos diretos e indiretos. Isso mostra que a pesquisa envolvendo informática e avaliação na educação a distância tem se preocupado tanto com a aprendizagem em si, quanto com as condições em que ocorre a aprendizagem.

$\mathrm{Na}$ educação a distância, promover a regulação, seja direta ou indireta, das aprendizagens é um tanto mais complicado. Envolve, além da coleta de informações confiáveis e pertinentes, agilidade e imparcialidade no processamento dessas informações no nível de sua apropriação para tomada de decisão. Tudo isso em tempo hábil para a adequação das intervenções reguladoras e assimilação pelos alunos do feedback, que recebem. Daí a importância do contínuo desenvolvimento e expansão da pesquisa sobre o uso da informática como suporte ao processo de avaliação na educação a distância.

Quanto ao Enfoque dos Trabalhos analisados é possível constatar uma forte tendência de pesquisa sobre formas de rastreamento da aprendizagem e das atitudes e estados dos alunos. Ganham destaque o desenvolvimento de agentes inteligentes, adaptabilidade dos ambientes virtuais de aprendizagem e sistemas para gerenciamento, criação e aplicação de exercícios. 
Tais tipos de recursos e tecnologias estão perfeitamente alinhados com os ideais de uma avaliação que se pretende formativa, uma vez que tratam de prover instrumentos para avaliação, além de ajudar a observar o entorno da aplicação de tais instrumentos. Além disso, tratam de adaptar os caminhos da aprendizagem aos passos de cada aluno. E talvez aí resida a dificuldade de se transformar a avaliação formativa numa prática tão corrente quanto desejamos. A necessidade de adaptabilidade ao processo dos alunos faz com que tenhamos que admitir bem mais do que uma maneira de regular a ação pedagógica. "A avaliação formativa introduz uma ruptura porque propõe deslocar essa regulação ao nível das aprendizagens e individualizá-la" (PERRENOUD, 1999, p. 15).

\section{CONSIDERAÇÕES FINAIS}

Os resultados encontrados, embora mostrem um ponto preocupante, que é falta de utilização de referenciais teóricos sobre avaliação em boa parte dos trabalhos analisados, mostram também que a pesquisa e a produção científica na UFRGS nos últimos anos têm trilhado um bom caminho no sentido qualitativo. Têm se preocupado em estudar a colocação da informática à serviço de professores e alunos no sentido de contribuir para a viabilidade de uma perspectiva formativa da avaliação na educação a distância.

Por viabilidade entendemos a ocorrência de resposta satisfatória e feedback em tempo hábil para os estudantes e que existam pistas suficientes para a intervenção reguladora do processo pelos professores ou tutores, mesmo quando estes têm um grande número de alunos sob sua orientação.

O número de trabalhos voltados para o rastreamento ou monitoramento das atitudes e ações de participação dos alunos em ambientes virtuais indica uma aposta na regulação indireta da aprendizagem. Uma aposta de que se um aluno está interagindo satisfatoriamente num enfoque quantitativo e qualitativo é porque deve estar aprendendo na mesma proporção. Da mesma forma encontramos trabalhos cujos objetivos envolvem o fornecimento de informações sobre a aprendizagem para alunos e professores.

Entretanto, nossa análise dos resultados encontrados sugere a necessidade de mais pesquisas sobre como consolidar ou sumarizar as informações obtidas a partir do rastreamento das ações dos alunos. Acreditamos que tal consolidação ou sumarização pode ser útil para agilizar a tomada de decisão para intervenções de regulação no processo e nas condições da aprendizagem.

Num outro pólo, notamos a baixa ocorrência de pesquisas sobre os efeitos práticos dos feedbacks recebidos pelos alunos sobre seus processos e condições de aprendizagem.

E, para finalizar, retomando o cenário de expansão da educação a distância descrito na seção Introdução, consideramos que o número encontrado de artigos, dissertações e teses sobre informática e avaliação na educação a distância poderia ser maior. Mesmo, sabendo que a metodologia utilizada não alcançou a totalidade dos trabalhos na área.

Fica, então, a sugestão e o incentivo para que trabalhos futuros na área da Informática na Educação abordem o tema avaliação na educação a distância tentando aperfeiçoar o que já foi desenvolvido e suprir as carências aqui apontadas. 


\section{REFERÊNCIAS BIBLIOGRÁFICAS}

AZZI, Sandra. Avaliação de desempenho do aluno na ead. Salto para o Futuro: Avaliação na EaD. Disponível em:

<http://www.tvebrasil.com.br/SALTO/boletins2002/ead/eadtxt5a.htm>. Acesso em: 22 dez. 2006.

BLOOM, B. et al. Manual de Avaliação Formativa e Somativa do Aprendizado Escolar. S. Paulo: Livraria Pioneira Editora, 1983.

FERREIRA, Thaisa B.; OTSUKA, Joice L.; ROCHA, Heloísa V. da. Interface para Auxílio à Avaliação Formativa no Ambiente TelEduc. In: SIMPÓSIO BRASILEIRO DE INFORMÁTICA NA EDUCAÇÃO, 14., 2003, Rio de Janeiro. XIV Simpósio Brasileiro de Informática na Educação - SBIE. Rio de Janeiro: UFRJ, 2003. p. 1 10. Disponível em: <http://www.dcc.unicamp.br/ joice/artigos/artigo_sbie_tjh.PDF>. Acesso em: 22 dez. 2006.

HADJI, Charles. A avaliação, regras do jogo: das intenções aos intrumentos. 4. ed. Portugal: Porto Editora, 1993. 190 p.

HADJI, Charles. Avaliação desmistificada. Tradução de Patrícia Ramos. Porto Alegre: Artes Médicas, 2001.

INEP. Educação a Distância cresce mais ainda entre os cursos superiores. 2007. Disponível em: <http://www.inep.gov.br/imprensa/noticias/censo/superior/news07_01.htm>. Acesso em: 20 maio. 2008.

PALLOFF, Rena M. ; PRATT, Keith. O aluno virtual: um guia para se trabalhar com estudantes on-line. Porto Alegre: Artmed, 2004.

PERRENOUD, P. Avaliação: da excelência à regulação das aprendizagens. Porto Alegre: Artmed, 1999. 